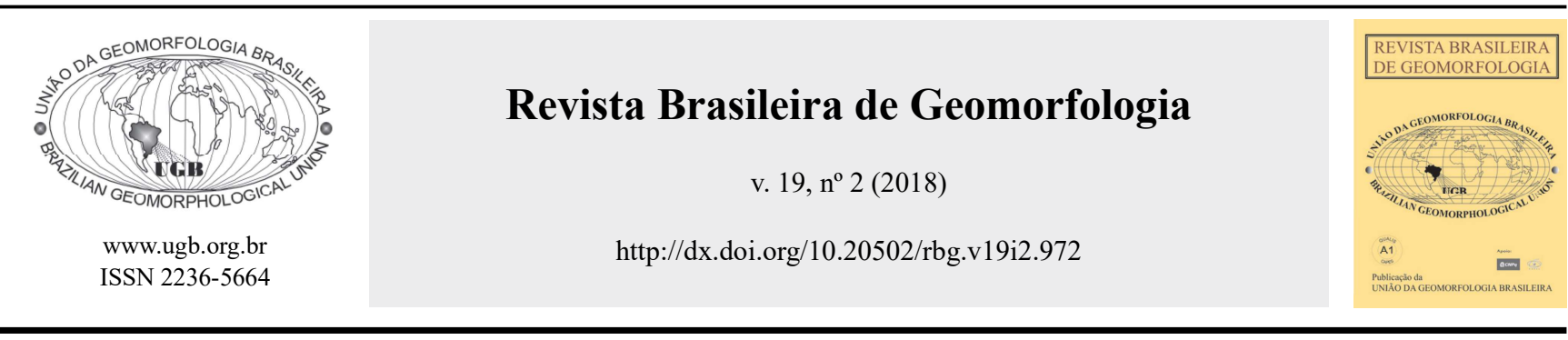

\title{
EVOLUÇÃO GEOMORFOLÓGICA DO RIO GRANDE, RJ: INFLUÊNCIAS GEOLÓGICAS E CAPTURAS DE DRENAGEM
}

\section{GEOMORPHOLOGICAL EVOLUTION OF GRANDE RIVER, RJ: GEOLOGICAL INFLUENCES AND RIVER CAPTURE}

\author{
Rodrigo Wagner Paixão Pinto \\ Departamento de Geografia e Meio Ambiente, Pontificia Universidade Católica do Rio de Janeiro \\ Rua Marquês de São Vicente, 225, Rio de Janeiro, Rio de Janeiro. CEP: 22451-900. Brasil \\ Email: rodrigo_paixao@puc-rio.br \\ Marcelo Motta de Freitas \\ Departamento de Geografia e Meio Ambiente, Pontifícia Universidade Católica do Rio de Janeiro \\ Rua Marquês de São Vicente, 225, Rio de Janeiro, Rio de Janeiro. CEP: 22451-900. Brasil \\ Email:marcelomotta@puc-rio.br
}

Julio Cesar Horta de Almeida

Departamento de Geologia, Universidade do Estado do Rio de Janeiro Rua São Francisco Xavier, 524, Rio de Janeiro, Rio de Janeiro. CEP: 20550-900. Brasil

Email: jchalmeida@gmail.com

Luiz, Guilherme Almeida do Eirado Silva

Departamento de Geologia, Universidade do Estado do Rio de Janeiro Rua São Francisco Xavier, 524, Rio de Janeiro, Rio de Janeiro. CEP: 20550-900. Brasil

Email: lgeirado@gmail.com

\section{Informações sobre o Artigo}

Recebido (Received):

08/01/2018

Aceito (Accepted):

$27 / 02 / 2018$

\section{Palavras-chave:}

Evolução Geomorfológica; Capturas de Drenagens; Bacia Hidrográfica do Rio Grande-RJ.

\section{Keywords:}

Geomorphologic Evolution; River Capture; Grande River.

\section{Resumo:}

A análise dos sistemas fluviais é de grande importância na compreensão da evolução geomorfológica da paisagem, pois possuem características, seja no seu arranjo ou distribuição dos canais, que auxiliam no entendimento da sua evolução ao longo do tempo. A ruptura do continente Gondwana e seus múltiplos eventos até a consolidação do Rift Continental do Sudeste do Brasil (RCSB) implicou em uma mudança significativa no relevo sudeste e, consequentemente, nos sistemas de drenagens. Isto promoveu a reorganização dos sistemas de drenagens e uma nova dinâmica hidro-erosiva pelo rebaixado do nível de base nosetor leste do continente. Diante do exposto, selecionou-se como estudo de caso a bacia hidrográfica do Rio Grande no estado Rio de Janeiro com o objetivo principal de entender o processo de evolução geomorfológica da bacia, a partir da organização da rede de drenagem e feições elementares da bacia frente aos eventos geológicos de formação e estruturação do substrato rochoso durante o Neoproterozoico e, posteriormente, no Cretáceo. A metodologia utilizada se baseia em trabalhos de gabinete, de campo e posterior análise dos dados gerados. Pode-se inferir que a 
evolução geomorfológica da bacia do Rio Grande foi influenciada pelos múltiplos eventos tectônicos do RCSB, como na reativação de estruturas pretéritas que condicionaram os eixos de drenagem. Os dados demonstram forte controle do substrato rochoso na morfologia do relevo e na orientação da rede de drenagem. Os resultados das orientações dos fluxos de drenagem demonstram grande quantidade de rios nas orientações NE, assim como, boa parte dos lineamentos estruturais na bacia estudada. Destaca-se, a influência dos lineamentos minerais das rochas, principalmente os gnaisses da Unidade São Fidélis para este comportamento. Além disso, lineamentos estruturais em outras direções influenciaram na formação de anomalias de drenagem e capturas de drenagens. Ao todo, foram analisados 17 knickpoints e percebeu-se que quando associados aos granitos, apresentam como característica a formação de quedas d'água, enquanto que boa parte dos níveis de base sobre rochas da Unidade São Fidélis possuem característica típica de corredeiras. Acredita-se que a região correspondeu a um extenso planalto de altitude mais elevada que a atual, e sistema fluvial com direção predominante para noroeste/norte. A evolução da bacia do Rio Grande se deu com o avanço das drenagens atlânticas sobre o antigo Planalto Sudeste, através da erosão remontante e controladas pelo nível de base.

\begin{abstract}
:
Analysis of river systems is of great importance in understanding the geomorphological landscape evolution because they have characteristics, either in their arrangement or distribution of channels on which to build their evolution over time. Rupture of the Gondwana continent and its multiple events to the consolidation of the Continental Rift of Southeast Brazil (RCSB) resulted in a significant change in Southeast relief and consequently the drainage systems. This promoted the reorganization of drainage systems and a new hydro-erosive dynamic demoted by the basic level in the eastern sector of the continent. Concerning what was mentioned, was selected as a case study the basin of the Rio Grande in Rio de Janeiro with the main objective to understand the process of geomorphological evolution of the basin from the drainage network organization and basic features of the front basin to the events geological formation and structure of the bedrock. The methodology is based on office work, field and subsequent analysis of the data generated. It can be inferred that the geomorphological evolution of the Rio Grande basin was influenced by multiple tectonic events RCSB as the reactivation of preterit structures that conditioned the drainage shafts. The data demonstrate strong control of bedrock in relief morphology and orientation of the drainage network. The results of the guidelines of the drainage flows demonstrate large number of rivers in NE guidelines, as well as many of the structural lineaments in the studied basin. Noteworthy is the influence of minerals lineaments of rocks, especially gneisses of St. Fidelis Unit for this behavior. In addition, structural lineaments in other directions influenced the formation of drainage anomalies and drainage catch. In all, they analyzed 17 knickpoints and realize that when associated with granites, have the characteristic of formation of waterfalls, while much of the base levels on rocks of St. Fidelis Unit have typical characteristic of rapids. It is believed that the region corresponding to an extensive plateau of higher altitude than the current, and river system with predominant direction to north / north. The evolution of the Rio Grande basin was through the advancement of the Atlantic drainages on the old Plateau Southeast, through remontant erosion and controlled by the basic level.
\end{abstract}

\section{Introdução}

Entender a evolução geomorfológica da paisagem remete-nos, também, ao entendimento dos sistemas de drenagem, pois, os mesmos trazem consigo características intrínsecas à história de evolução da paisagem. A conformação, arranjo e distribuição dos canais fluviais tornam-se fundamentais para a junção dos episódios evolutivos que modelaram e moldam a superfície terrestre (SILVA\& SANTOS, 2010). Neste sentido, a identificação de anomalias, tais como, mudanças abruptas nas direções dos cursos d'água constituem uma ferramenta importante para a reconstituição paleogeográfica da rede de drenagem e, portanto, da evolução do relevo.

A reconstituição de eventos erosivo-deposicionais durante o Quaternário, principalmente, no Planalto Sudeste Brasileiro tem sido objeto de estudo de diferentes pesquisadores que empregam diferentes métodos em suas abordagens(BIGARELLA \& MEIS, 1965; MOURA \& MEIS, 1980; SILVA, 
1991;LIMA, 2000; FERRARI, 2001; SILVA et al., 2006; RICCOMINI et al., 2010).

O relevo da região foi bastante influenciado por esforços tectônicos durante o ciclo brasiliano pelo amalgamento de placas e, posteriormente, pela abertura do Rift Continental do Sudeste do Brasil (RCSB) durante o Paleógeno, (RICCOMINI et al., 2010; AB'SABER, 1957). Estes movimentos resultaram em estruturas geológicas que foram de extrema importância na configuração atual do relevo da Região Sudeste do Brasil como demonstrado por Ruellan (1944) ao analisar a evolução geomorfológica da Baía de Guanabara. Diferentes estudos abordam as transformações na paisagem do Planalto Sudeste Brasileiro, tanto através dos eventos tectônicos ocorridos no final do Cretáceo, quanto pela interpretação estratigráfica de depósitos e mudanças climáticas durante o Quaternario (RICCOMINI, 1989;DANTAS, 1995; COELHO NETTO, 1999; MOURA, 1990; LIMA, 2000;FERRARI, 2001; COELHO NETTO, 2003;).

A quebra do continente Gondwana e seus múltiplos eventos até a consolidação do RCSB implicou em uma mudança significativa no relevo e, consequentemente, nos sistemas de drenagens (ASMUS \& FERRARI, 1978; RICCOMINI et al., 2010). Uma das principais características desses eventos são as reativações de estruturas brasilianas, bem como, o soerguimento e abatimento de blocos crustais que serão aprofundados mais adiante (RICCOMINI et al., 2004). Isto promoveu a reorganização dos sistemas de drenagens e uma nova dinâmica hidroerosiva pelo rebaixamento do nível de base no setor leste do continente com a consolidação do Rift Cenozoico do Sudeste do Brasil. (ZALÁN \& OLIVEIRA., 2005; RICCOMINI et al., 2010)

Diversos autores chamam atenção para o sistema de capturas do rio Paraíba do Sul dos sistemas fluviais da região Sudeste, associados à quebra do supercontinente Gondwana, formação do RCSB e rebaixamento do nível de base. Neste sentido, destaca-se a captura do Alto Tietê pelo rio Paraíba do Sul (AB'SABER, 1957; OLIVEIRA, 2003). O mesmo pode ter ocorrido para os cursos d'água que, atualmente, drenam para este rio e, preteritamente, apresentavam outra conformação dos sistemas fluviais e drenavam para paleobacias. Sobre a dinâmica de capturas, estudos como o de Cheremet al. (2012), Oliveira (2003), Ab'Saber (1957), Pasa (2013) dentre outros demonstram o avanço do sistema de drenagem do rio Paraíba do Sul em detrimento das bacias adjacentes, como a do rio Paraná, rio São Francisco e rio Doce.

Diante do exposto, selecionou-se como estudo de caso a bacia do rio Grande, localizada no estado do Rio de Janeiro, por ser um dos afluentes do rio Paraíba do Sul e estar diretamente associado aos eventos tectônicos mencionados anteriormente que influenciaram o relevo da região. A bacia do rio Grande situa-se no reverso da Serra do Mar e, através da tectônica cenozoica e a consolidação do RCSB, pode ter sofrido mudanças significativas na estrutura e arranjo da dinâmica hidrológica da região, afetada por pulsos erosivos ao longo do tempo. Atualmente, está submetida a uma dissecação associada ao nível de base do RCBS e apresenta inúmeras evidências de controle litoestrutural da rede de drenagem, que podem ser evidenciados por cotovelos de drenagem e vales abandonados. Estas anomalias de drenagem e a ocorrência de níveis de base locais ao longo da bacia podem ser evidências do controle de estruturas geológicasno sistema de drenagem da bacia e, por isso, são objetos de estudo do presente artigo.

\section{Área de Estudo}

O estado do Rio de Janeiro, situado na Região Sudeste do país, está geotectonicamente contido na Província Mantiqueira, uma das províncias estruturais definidas por Almeida et al. (1981). Esta província cobre uma extensa área sendo bastante afetada pelo Ciclo Orogênico Brasiliano, durante o Neoproterozoico/ Cambriano. A Província Mantiqueira representa uma entidade geotectônica com franca orientação nordestesudoeste instalada a leste do Cráton do São Francisco ao final do Neoproterozoico e início do Paleozoico, constituindo, juntamente com a Faixa Brasília e o Cráton de São Francisco, o arcabouço geotectônico do Sudeste Brasileiro (ALMEIDA et al., 1981; ALMEIDA \& CARNEIRO, 1998).

A bacia do rio Grande está entre os paralelos $22^{\circ} 25^{\prime} \mathrm{S} / 21^{\circ} 35^{\prime} \mathrm{S}$ e os meridianos $42^{\circ} 45^{\prime} \mathrm{W} /$ $41^{\circ} 45^{\prime} \mathrm{W}$. Localiza-se no Planalto Sudeste Brasileiro abrangendo parte de 11 municípios, da região serrana do estado do Rio de Janeiro, sendo eles: Bom Jardim, Cantagalo,Cordeiro, Duas Barras, Itaocara, Macuco, Nova Friburgo, Santa Maria Madalena, São Fidélis, São Sebastião do Alto e Trajano de Morais. Situa-se no reverso da Serra do Mar e perpassa por distintos compartimentos do relevo, variando desde escarpas 
serranas até planícies fluviais. Suas nascentes ocorrem no município de Nova Friburgo, podendo atingir aproximadamente 1.400 metros de altitude, e sua foz se dá em sua confluência com o rio Paraíba do Sul próximo à cidade de São Fidélis na altitude de 20 metros aproximadamente (Figura 1).

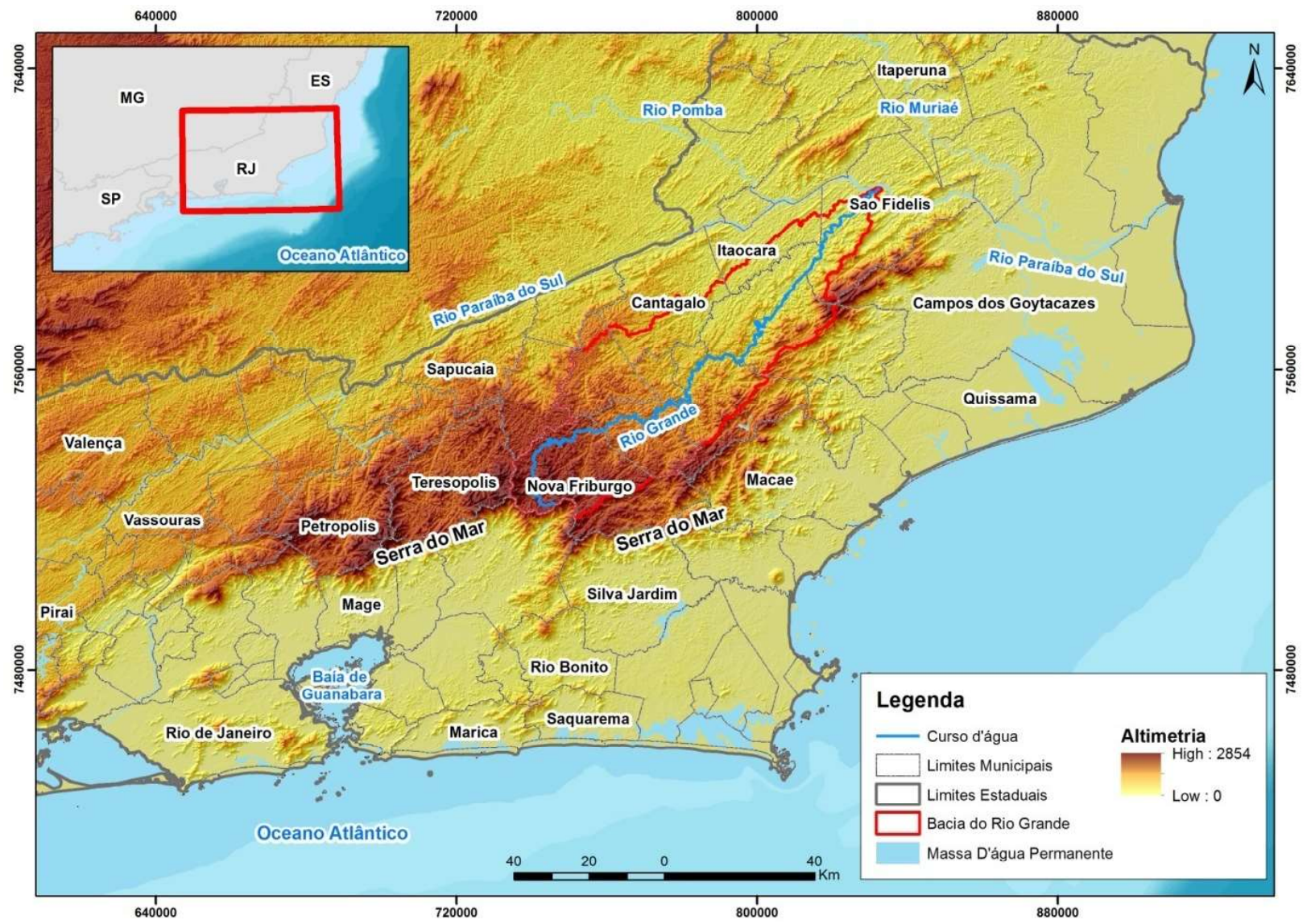

Figura 1 - Localização da Bacia do rio Grande e o aspecto do relevo do Planalto Sudeste Brasileiro.

O clima da região é o tropical úmido que se caracteriza por duas estações bem definidas. No verão há concentração das chuvas, enquanto que no inverno ocorre período de estiagem. A precipitação média anual é de aproximadamente $1.200 \mathrm{~mm}$ e as temperaturas médias ficam entre $20^{\circ}$ e $25^{\circ}$ (LAMEGO, 1963).

Em relação à geologia, a região estudada situa-se no segmento central da Faixa Ribeira de idade Neoproterozoica (HEILBRON et al., 2004; TUPINAMBÁ et al., 2012) no ciclo termotectônico de caráter dúctil denominado Brasiliano na configuração do supercontinente Gondwana acarretou em um complexo cinturão de dobramentos e empurrões na atual margem do sudeste brasileiro. A Faixa Ribeira é divida em quatro terrenos tectonoestratigráficos imbricados para NW/W em direção ao Cráton de São Francisco, sendo eles: Terreno Ocidental,Terreno Paraíba do Sul,Terreno Oriental e Terreno Cabo Frio (HEILBRON et al., 2004;
TUPINAMBÁ et al., 2007; TUPINAMBÁ et al., 2012). Em termos estruturais tal processo colisional leva as unidades litológicas a um alinhamento de orientação NE-SW, justamente paralelo à direção da colisão. Após estabilidade crustal de aproximadamente 300 milhões de anos, ocorreram novos esforços tectônicos associados à abertura do oceano Atlântico que culminou em padrões de fraturamentos alinhados nas orientações N-S, NESW (HEILBRON et al., 1995; HEILBRON et al., 2004).

De acordo com o Mapa Geomorfológico do Estado do Rio de Janeiro elaborado por Dantas (2001), a bacia do rio Grande é formada pelos seguintes compartimentos de relevo: Alinhamentos Serranos e Degraus Estruturais, Domínio Colinoso - Mar de Morros, Domínio de Colinas Dissecadas, Domínio de Morros Elevados e Pães-de-Açúcar, Domínio Montanhoso, Escarpas Serranas Degradadas e Degraus em Borda de Planaltos e Planícies Aluviais. 
O planalto no qual está inserida a bacia estudada, preteritamente, pode ter sido muito mais extenso e com uma conformação de drenagem distinta da atual. Devido à sua localização na borda do RCSB acreditase que suas drenagens e a geomorfologia tenham sido influenciadas por esses eventos tectônicos associados à consolidação do RCSB. Neste sentido, a análise destas características pode contribuir na compreensão da evolução geomorfológica da bacia do rio Grande.

\section{Procedimentos Metodológicos}

Através do método hipotético-dedutivo, utilizou-se como base para a realização do trabalho o levantamento de informações bibliográficas, análises em ambiente SIG, trabalhos de campo e elaboração de mapas.

Os procedimentos para os mapeamentos foram elaborados a partir da base cartográfica do IBGE na escala de 1:50.000, entre os anos de 1968 - 1976 para a região. Neste sentido, foram utilizadas as cartas topográficas inseridas na área da bacia, totalizando 11 cartas, sendo elas: Além Paraíba, Duas Barras, Nova Friburgo, Quarteis, Cordeiro, Cantagalo, Trajano de Morais, Santa Maria Madalena, Renascença, Santo Antônio de Pádua e Cambuci. Além da base cartográfica do IBGE, as imagens de radar SRTM (Shuttle Radar Topography Mission) da NASA que foram ajustadas e corrigidas por pesquisadores da EMBRAPA Monitoramento por Satélite (MIRANDA, E. E. et al., 2005) auxiliaram na elaboração dos mapeamentos.

Foi elaborado, através do software ArcGIS, o perfil longitudinal do rio Grande sendo traçado desde a sua nascente até sua foz com o rio Paraíba do Sul, com o intuito de analisar a morfologia do perfil segundo as proposições elaboradas por Christofoletti (1977). Além disso, perfis topográficos foram elaborados para a identificação de topos coincidentes e vales com altitudes semelhantes, neste sentido, três traçados ao longo da bacia foram definidos para representar o alto, médio e baixo curso do rio Grande.

Os níveis de base foram identificados através da análise das curvas de nível extraídas das cartas topográficas do IBGE na escala de 1:50.000 utilizando o software Arcgis. A delimitação dessa feição geomorfológica se deu nos locais onde há uma concentração de curvas de nível que caracterizam um desnível topográfico abrupto e, também, quando as mesmas se aproximam formando um estrangulamento seguido de desnível para jusante. Após o mapeamento dos níveis de base em ambiente digital, realizaramse trabalhos de campo com o intuito de descrever as principais características dos mesmos.

Para o mapeamento das capturas de drenagem, identificaram-se as anomalias de drenagens, tais como mudanças abruptas na direção de drenagem, bem como, divisores rebaixados. Já os níveis de base foram mapeados através da interpretação e análise das curvas de nível disponíveis nas cartas topográficas na escala de 1:50.000 que abrangem a bacia em estudo. Soma-se a isso, a interpretação do perfil longitudinal do rio Grande que também auxiliou na identificação dos principais níveis de base a partir das rupturas de declive ao longo do perfil. Estes dados contribuíram no entendimento da evolução da rede de drenagem do rio Grande, juntamente com os dados acima mencionados.

\section{Compartimentação Topográfica da Bacia do Rio Grande}

A bacia do rio Grande caracteriza-se por um relevoalternando entre serras e colinas cortados por vales encaixados ou não, podendo formar planícies fluviais. Além disso, exibe um elevado grau de dissecação imposto pela drenagem, evidenciados por grandes variações altimétricas e movimentos de massa recentes. Os dados altimétricos auxiliaram na análise e no entendimento da morfologia do relevo desta bacia. Ao correlacionar os dados altimétricos com as unidades geológicas, deduz-se que os litotipos exercem influência na altitude do relevo (Figura 2).

No planalto elevado, próximo à cabeceira do rio Grande, ocorrem os Granitos pós-tectônicos, como o Granito Nova Friburgo, de idade Paleozoica - em relação às rochas da Unidade São Fidélis, por exemplo - e mais resistentes ao intemperismo e a erosão devido à sua isotropia, fazendo com que o relevo permaneça mais elevado. No caso das unidades mais resistentes, como o Granito Nova Friburgo e o Complexo Rio Negro, as rochas possuem menos planos de fraqueza, como a foliação presente nas rochas da Unidade SãoFidélis, o que contribui para a elevação das cotas altimétricas do relevo. Este comportamento também é observado ao longo dos divisores de drenagem da bacia hidrográfica do rio Grande nas porções mais elevadas da Serra do Mar, sendo os granitos bastante comuns nestas áreas, promovendo o surgimento de imponentes paredões rochosos na paisagem. 
Pinto R. W. P. et al.
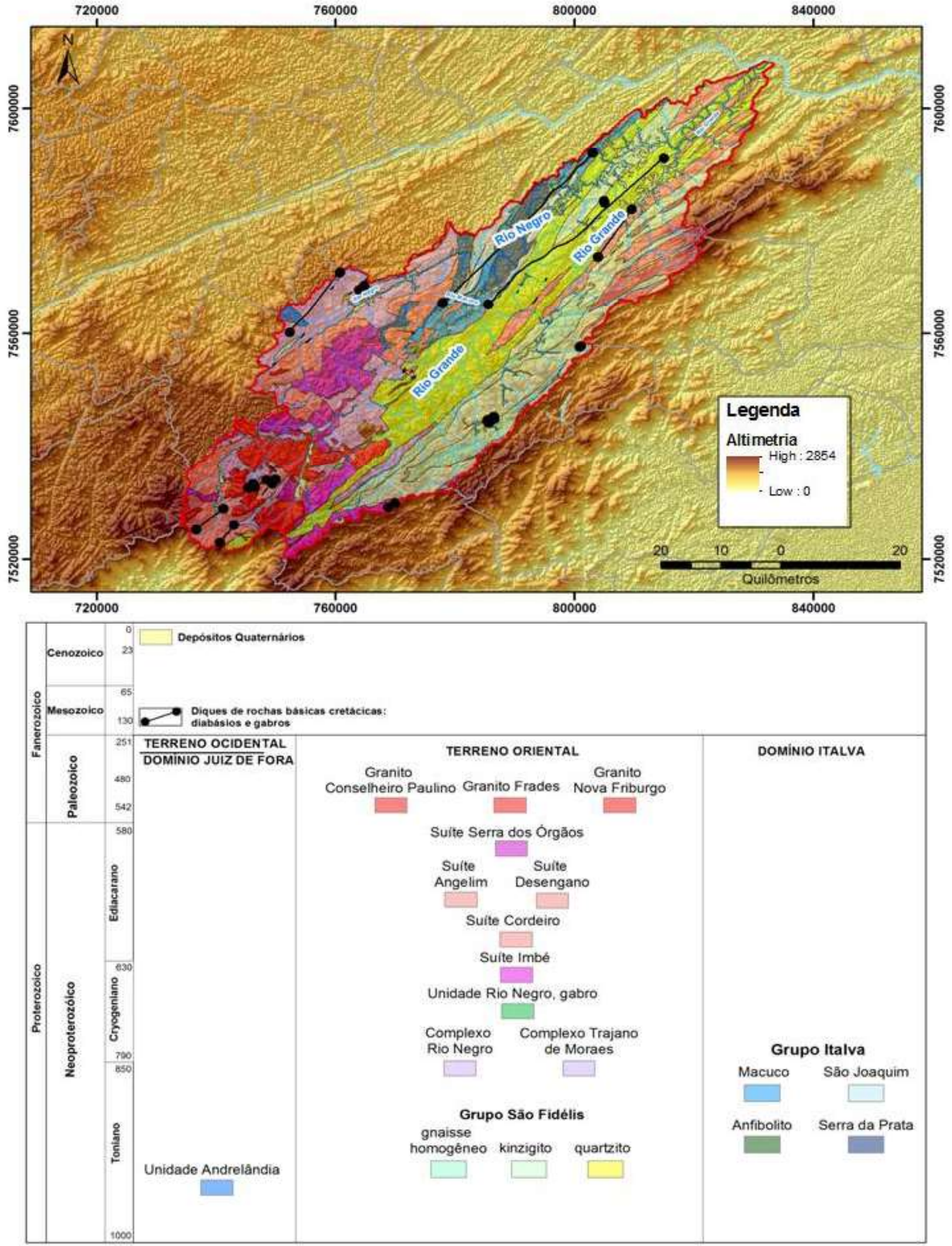

Figura 2 - Unidades Geológicas da Bacia do rio Grande sobrepostas à informações topográficas. (TUPINAMBÁ et al., 2012) 
Já nas áreas onde ocorrem as unidades geológicas São Fidélis e Italva o relevo apresenta cotas altimétricas menores, variando entre 160 e 20 metros. Estas rochas caracterizam-se pela baixa resistência ao intemperismo e erosão proporcionada por fraturas e foliação marcante, como os gnaisses e os kinzigitos, permitindo assim, maior disseção e rebaixamento do relevo (TUPINAMBÁ et al. 2007). Soma-se à isso, as estruturas geológicas da região, tais como a foliação dos gnaisses na direção NE-SW e as fraturas (juntas) com a mesma direção, que contribuem para o trabalho erosivo nessas unidades.

Em relação aos perfis topográficos, atentou-se para que os mesmos fossem traçados transversais ao curso do rio Grande para análise de mudança do relevo na calha e adjacências. A localização na bacia e os perfis topográficos podem ser visualizados nas Figuras 3 e 4 .

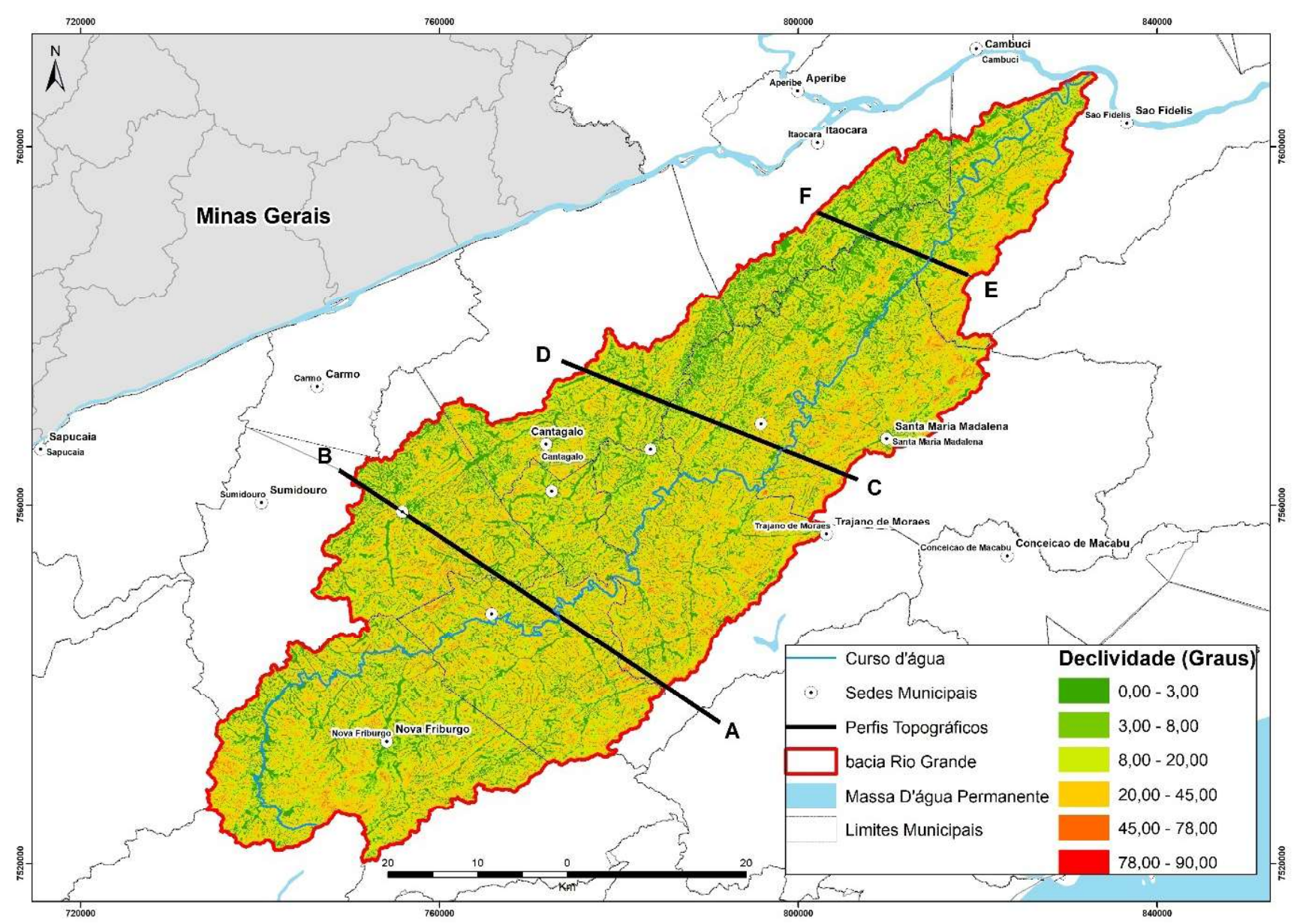

Figura 3 - Localização dos perfis topográficos elaborados na bacia do rio Grande (MIRANDA, et al. 2013).

O perfil topográfico A-B fica em um setor mais elevada em relação aos outros dois perfis e tem um desnível topográfico bastante elevado, de aproximadamente $800 \mathrm{~m}$. Seu ponto mais alto chega a atingir aproximadamente $1.400 \mathrm{~m}$ na Serra da Boa Vista, um dos divisores da bacia, e o ponto mais baixo o situado na calha do rio Grande a 500 metros de altitude. Percorre por relevo de morros e serras em altitudes variando entre $900 \mathrm{~m}$ e $700 \mathrm{~m}$ intercalados por vales, em sua maioria encaixados, com destaque para a Serra da Pena que forma um divisor de drenagem entre os afluentes do rio Grande e rio Negro. Além disso, é possível identificar dois vales suspensos no perfil topográfico de extensão considerável, sugerindo controle de nível base local.Dentre eles, destaca-se o vale do rio Macuquinho têm sua formação associada a um nível de base local formado por erosão diferencial das rochas do Complexo Rio Negro e da Suíte Serra dos Órgãos. 
Pinto R. W. P. et al.
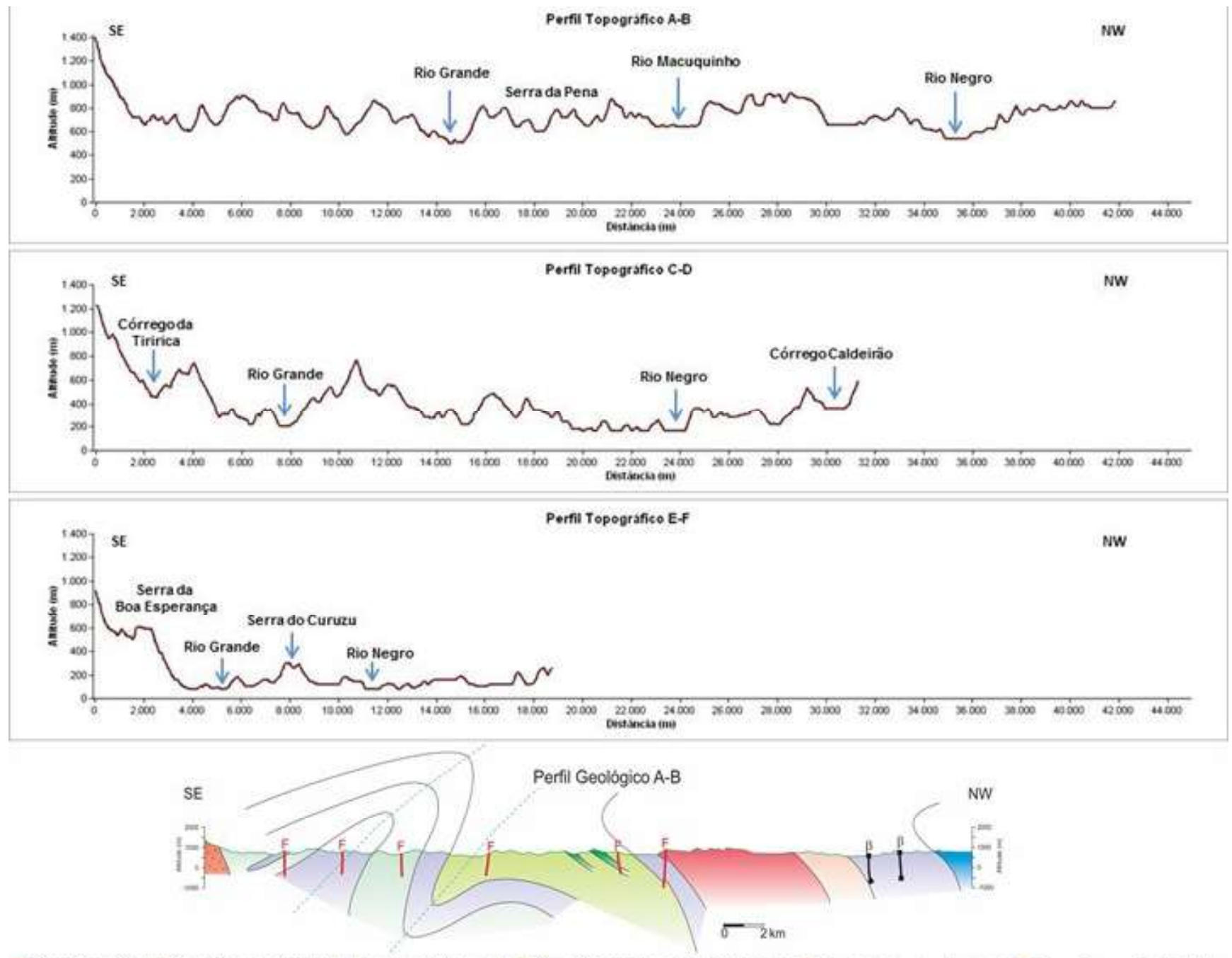

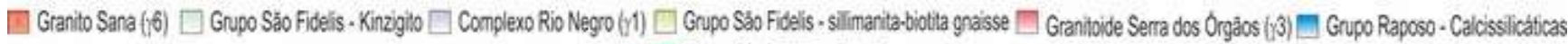

$$
\text { F. Falha } \quad \beta \text { - Dique }
$$

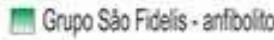

$\square$ Grantiode Cordero (2)

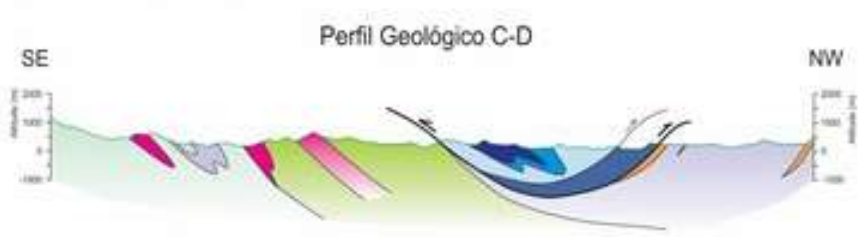

Granitoide Serra de Sẫo Pedro ( 2 )

Grupo São Fidelis - Kinzigito $\square$ Grupo Săo Fidelis - sillimanita-biotita gnaisse

$$
\text { - Falha de Empurrăo }
$$
Suite Serra da Prata
Grupo Italva - Macuco - anfibólio gnaisse

Grupo ltalva - São Joaquim - mármore

Grupo Italva - Euclidelândia - biotita gnaisse

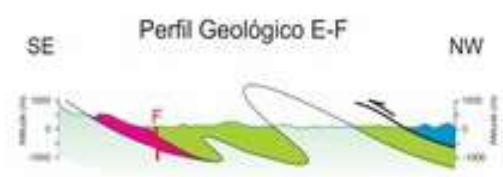

Granitoide Serra de São Pedro (†2) Grupo Italva - Macuco - anfibólio gnaisse Grupo São Fidelis - Kinzigito Grupo São Fidelis - sillimanita-biotita gnaisse F. Falha - Falha de Empurrão

Figura 4 - Perfis Topográficos elaborados transversais à na bacia do rio Grande. Fonte: HEILBRON, et al. (2016). 
Ao analisar o perfil C-D observa-se um desgaste do relevo principalmente na calha do rio Grande, indicando maior dissecação vertical dos vales neste trecho, pela formação do desnível altimétrico. Apesar disso, seu divisor da vertente da Serra do Mar alcança $1.200 \mathrm{~m}$ de altitude, enquanto que o divisor da vertente norte apresenta apenas $600 \mathrm{~m}$. A amplitude de relevo é de aproximadamente $1.000 \mathrm{~m}$ uma vez que os vales mais baixos se encontram em $200 \mathrm{~m}$ de altitude, podendo ser explicado pela presença das rochas menos resistentes ao intemperismo e erosão da Unidade São Fidélis e Unidade Italva. O relevo associado à estas unidades é mais rebaixado, enquanto que as porções mais elevadas estão relacionados à litotipos menos dissecados, como a Suíte Desengano. A porção mais elevada deste perfil é representada por montanhas da Serra do Mar, atingindo $1.200 \mathrm{~m}$ de altitude, enquanto que outras serras, como a Serra do Castelo e a Serra de São Sebastião do Alto,apresentam elevações semelhantes entre si, variando em tornode $750 \mathrm{~m}$ e $800 \mathrm{~m}$. Chama a atenção, também, alguns vales suspensos nivelados em altitudes semelhantes, alguns na faixa de $400 \mathrm{~m}$ e outros na faixa de $200 \mathrm{~m}$. Nota-se que o perfil mostra o vale do rio Grande na altitude de $200 \mathrm{~m}$ e o rio Negro em 220 aproximadamente.

Assim como os outros perfis analisados, o perfil E-F também apresenta uma amplitude de relevo elevada próximo ao divisorda Serra do Mar, contudo, a amplitude de relevo diminui conforme o perfil se aproxima do rio Grande e do rio Negro. Nesta porção do perfil, apenas lineamentos da Serra do Caruzu aumenta a amplitude de relevo. Isto pode ser explicado pela maior resistência litológica das rochas que ocorrem nestas áreas, como os granitos, atribuindo uma morfologia topográfica imponente na paisagem. Contudo, pode-se perceber que a altitude desse divisor também diminui em relação aos outros perfis, assim como o relevo. Neste perfil, a maior altitude é em torno de $850 \mathrm{~m}$, na Serra do Monte Alegre. O relevo é bastante dissecado nesta área, predominando apenas colinas isoladas e planícies fluviais, com exceção da Serra do Caruzu com 300m. De maneira geral, o relevo se dá entre $50 \mathrm{~m}$ e $150 \mathrm{~m}$ e o vale do rio Grande encontra-se em $80 \mathrm{~m}$ de altitude.

O canal principal do rio Grande percorre pouco mais de $230 \mathrm{~km}$ desde a sua nascente na região serrana do Rio de Janeiro, até sua confluência com o rio Paraíba do Sul perto da área urbana de São Fidélis. O rio Grande nasce numa altitude bastante elevada $-1.420 \mathrm{~m}$ - e desagua em cerca de $20 \mathrm{~m}$ de altitude, possuindo, portanto, gradiente topográfico acentuado de mais de $1.000 \mathrm{~m}$. Diante da análise do gráfico do perfil, podemos atribuir que o rio Grande percorre por quatro planaltos de altimetrias distintas, interrompidos por degraus topográficos caracterizados por níveis de base locais (Figura 5). Estas feições são de extrema importância na dinâmica hidrológica, pois, influenciam diretamente nos processos erosivos atuantes na bacia de drenagem. Neste sentido, pode-se dizer que estes níveis de base locais podem auxiliar na identificação de frentes de dissecação do relevo.

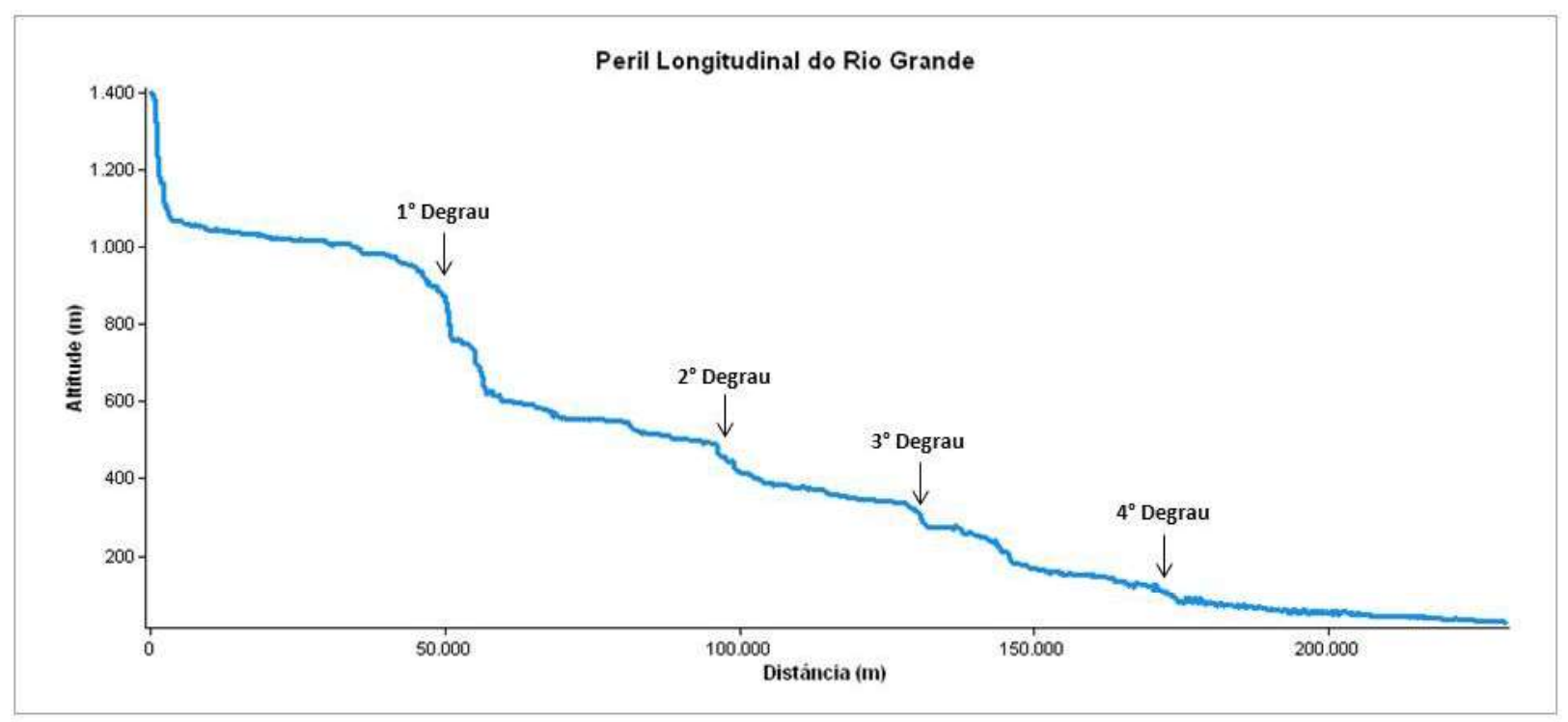

Figura 5 - Perfil Longitudinal do rio Grande. 
O primeiro degrau topográfico corresponde ao alto curso do rio Grande, apresentando uma amplitude de relevo considerável em $10 \mathrm{~km}$ de extensão, desde sua nascente até atingir o vale suspenso na localidade de São Lourenço. A altitude mais elevada é $1.400 \mathrm{~m}$ e a menor é, aproximadamente, $1.040 \mathrm{~m}$. Em relação à geologia, afloram rochas da Suíte Cordeiro e da Unidade São Fidélis. O segundo degrau topográfico, situa-se próximo à localidade de Riograndina após o rio Grande drenar por $50 \mathrm{~km}$ sobre uma superfície suavizada, com desnível topográfico de $400 \mathrm{~m}$ aproximadamente. Este degrau topográfico é marcado pela ocorrência de um nível de base associado ao contato litológico entre o Corpo Gabro e o Complexo Rio Negro, assim como as fraturas ortogonais ao eixo de drenagem.

O terceiro degrau corresponde ao trecho entre Riograndina até ruptura de declive do relevo à jusante da PCH Santa Rosa (aproximadamente ao atingir 100km de drenagem). O desnível altimétrico deste compartimento gira em torno de $300 \mathrm{~m}$ em $50 \mathrm{~km}$ de percurso, além disso, o rio drena, em sua maioria, sobre rochas associadas à Unidade São Fidélis, além de litotipos do Complexo Rio Negro e da Suíte Serra dos Órgãos. Estas duas unidades correspondem às porções mais elevadas do relevo deste compartimento. Outro degrau topográfico no rio Grande pode ser definido próximo à $150 \mathrm{~km}$ de distância da sua nascente, em ruptura de declive conhecida como Garganta do Roncador. A amplitude de relevo do perfil longitudinal do rio Grande deste compartimento é de $250 \mathrm{~m}$ em $40 \mathrm{~km}$ de extensão, e apresenta afloramentos da Unidade São Fidélis e da Suíte Desengano. No local do degrau da Garganta do Roncador, o eixo de drenagem está orientado pela foliação dos gnaisses e fraturas ortogonais proporcionam a formação da ruptura de declive.Por fim, ao atingir quase $170 \mathrm{~km}$ de drenagem o último degrau topográfico corresponde a um nível de base entre São Sebastião do Alto e Renascença, e a diferença altimétrica nesse compartimento é de $120 \mathrm{~m}$, apresentando relevo mais suave e vales mais alargados neste trecho. A geologia apresenta gnaisses típicos da Unidade São Fidélis e litotipos da Suíte Desengano.

\section{Lineamentos Estruturais e Orientação de Drenagem}

Em relação aos lineamentos, pode-se dizer que são encontrados em praticamente todas as direções sendo os de maior destaque aqueles de direções NESW e ENE-WSW que acompanham a calha do rio
Grande. Além dessas direções outra importante direção encontrada é a NW-SE. Ao analisar a frequência dos lineamentos através de diagrama de roseta, nota-se que a orientação N60E é predominante. Contudo, vale destacar a frequência dos lineamentos de direção N63W (Figura 6). Os lineamentos estruturais para NE-SW são condicionados, em sua maioria, por estruturas regionais dúcteis como a foliação e dobras que ocorrem na área de estudo, com plano-axial de N40E (TUPINAMBÁ, et al. 2012). Outro fator que influencia neste comportamento é o predomínio de contatos litológicos orientados nesta direção, favorecendo a formação de lineamentos no eixo NE-SW. As estruturas rúpteis representadas pelas fraturas (juntas) são responsáveis pelos lineamentos orientados para NW e possuem sua formação atrelada ao tectonismo Cenozoico pela reativação de antigas estruturas (HARTWIG \& RICCOMINI, 2010). É possível perceber que alguns vales suspensos estão orientados neste eixo, principalmente na porção sul e próximos aos divisores da Serra do Mar, vale destacar o vale do rio Macuquinho, mencionado anteriormente.

Orio Grande inicia seu curso com direção de fluxo para norte, controlado por um lineamento bem marcante no segmento N-S. Posteriormente, possui inflexões para NE próximo à localidade de Campo do Coelho. A partir de Riograndina, a calha principal deste rio segue a orientação principal NE, boa parte controlada pela foliação das rochas, contudo, muda de orientação em pequenos trechos influenciados por estruturas do substrato rochoso, como fraturas. Foi elaborada a roseta de orientação da rede de drenagem, levando em consideração todos os eixos de drenagem da bacia e o sentido do fluxo do rio, apresentando as direções NW e NE (Figura 7). Diante disso, destacase o controle geológico e estrutural na orientação e sentido da rede de drenagem. Além disso, estes dados estão diretamente relacionados com os lineamentos apresentados anteriormente, com destaque para o sentido do fluxo SW-NE, sendo influenciados em boa parte pela foliação dos gnaisses e contatos litológicos que ocorrem na bacia.

\section{Knickpoints}

Ao longo de toda extensão da bacia do rio grande foram identificados, através de interpretação das curvas de nível na escala 1:50.000, 380 knickpoints. 
Evolução Geomorfológica do Rio Grande, RJ: Influências Geológicas e Capturas de Drenagem

Para facilitar a logística do trabalho, diante da extensão territorial da bacia e da grande quantidade de knickpoints, optou-se pela análise dos níveis de base localizados no eixo principal do rio Grande e do rio
Negro. Neste sentido, 17 knickpoints foram visitados em campo e suas características são apresentadas no Quadro 1. Dentre estes pontos visitados, 13 encontramse no Rio Grande e apenas 4 no Rio Negro (Figura 8).

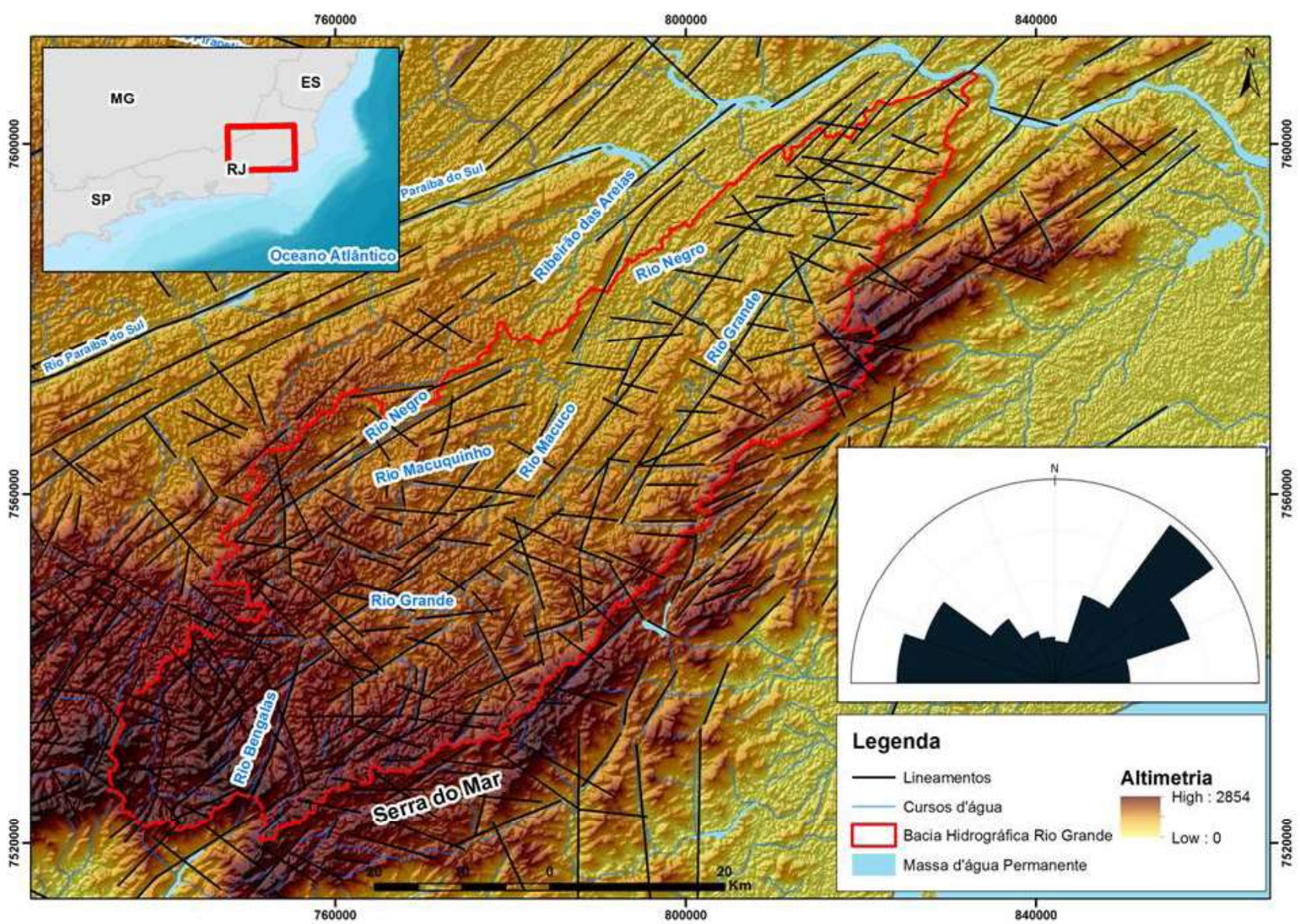

Figura 6 - Lineamentos na bacia do rio Grande e sua frequência absoluta.

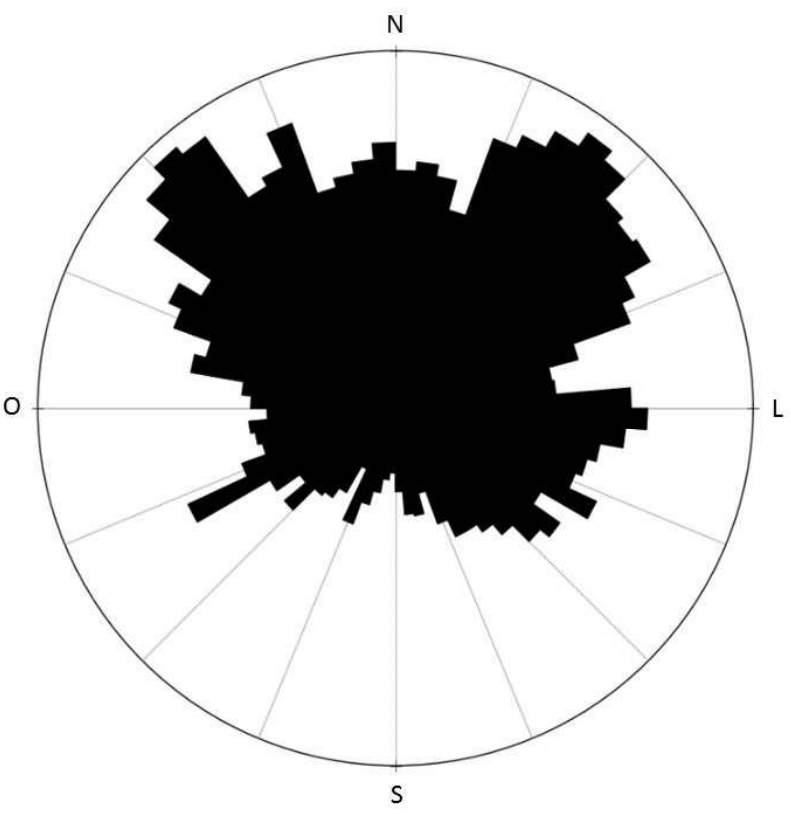

Figura 7 - Orientação da rede de drenagem do rio Grande. 


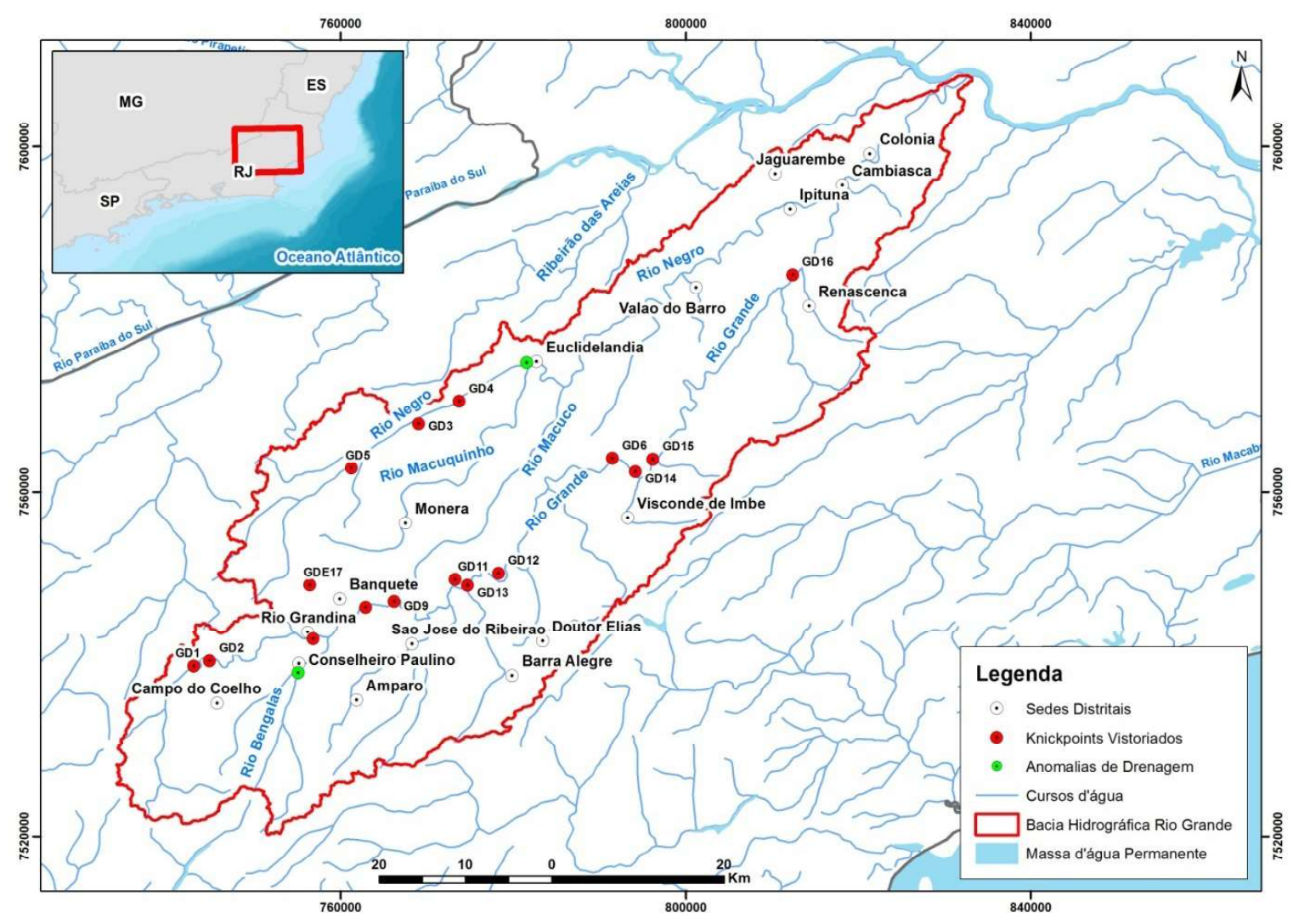

Figura 8 - Localização dos níveis de base vistoriados em campo ao longo da bacia.

Em relação à geologia dos knickpoints, de acordo com o mapeamento realizado no âmbito do PRONAGEO, os níveis de base distribuem-se em: 3 na Suíte Cordeiro; 1 Corpo Gabro; 5 no Complexo Rio Negro; 5 na Unidade São Fidélis (sillimanita-biotita gnaisse); 2 na Unidade São Fidélis (kinzigito). Percebe-se que os níveis de base associados aos granitos, apresentam como característica a formação de quedas d'água, enquanto que boa parte dos níveis de base sobre rochas da Unidade São Fidélis possuem característica típica de corredeiras (Figura 9). Isto ocorre devido à isotropia dos granitos, tendo como principal plano de fraqueza as fraturas, muitas delas ortogonais ao eixo de drenagem, promovendo a formação de quedas d'água e, consequentemente, cachoeiras. $\mathrm{O}$ Quadro 1 apresenta as principais características dos knickpoints, visitados em campo.

\section{Anomalias de drenagem}

As anomalias de drenagens identificadas na bacia em estudo podem contribuir no entendimento dos processos geomorfológicos da região. As anomalias de drenagem podem ser representadas por mudanças abruptas na orientação do canal de drenagem (CHRISTOFOLETTI, 1977; BISHOP, 1995). Foram identificadas 99 anomalias marcadas por mudanças abruptas na direção dos rios e ocorrência de vales secos, reforçando a ideia de que a bacia do rio Grande se desenvolveu numa dinâmica de frente erosiva capturando as drenagens remontantes. Além disso, em alguns casos são encontrados depósitos aluviais próximos aos divisores que são comuns em ambientes de capturas (BISHOP, 1995; SILVA, 2010).

Destacam-se, pelo menos, 2 anomalias de drenagem na bacia do rio Grande: uma no rio Bengalas no distrito de Conselheiro Paulino no município de Nova Friburgo e a do rio Negro no distrito de Euclidelândia no município de Cantagalo (Figura 8). No primeiro caso, o rio Bengalas, que drena no sentido norte na planície de Nova Friburgo até o Knickpoint de Conselheiro Paulino. Neste trecho, altera a direção do seu curso para NE em trechos encachoeirados até sua confluência com o rio Grande próximo à Banquete, deixando um vale abandonado entre Conselheiro Paulino até Riograndina.

Já a anomalia de drenagemno rio Negro, na altura do distrito de Euclidelândia, o eixo principal forma um cotovelo de drenagem seguido de desnível topográfico abrupto, formando um knickpoint. Além disso, a ocorrência de extenso vale seco, abandonado pela drenagem, com divisor rebaixado reforçam a possibilidade de ocorrência de capturas de drenagem, ou então, apenas se adaptouà fraturas e/ou falhas (Figura 10). 

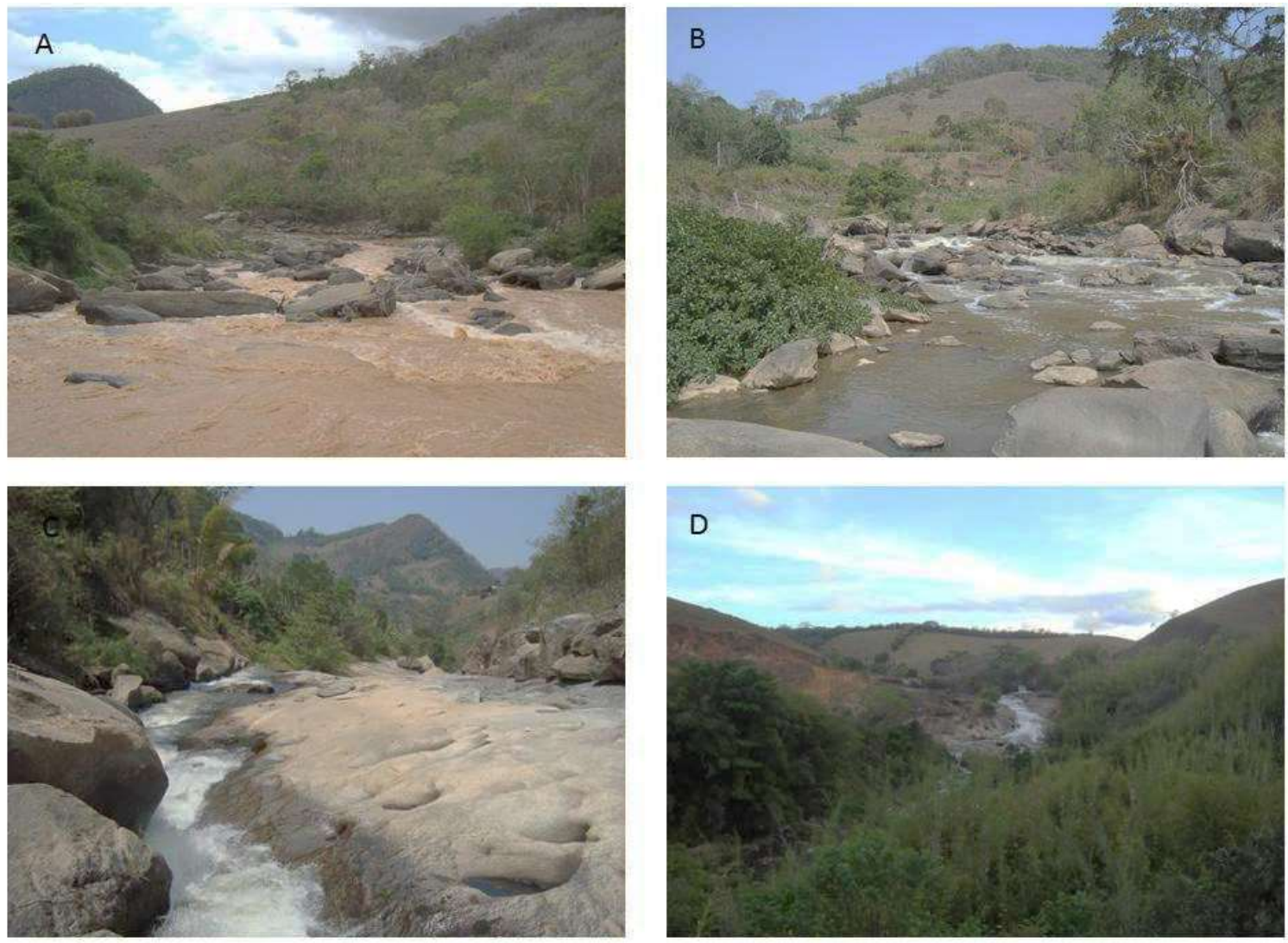

Figura 9 - Exemplo dos niveis de base identificados na bacia do rio Grande. Os exemplos A e B correspondem aos do tipo corredeira e os exemplos $C$ e D ao tipo queda d'água ou cachoeira.

Quadro 1: Principais características dos knickpoints vistoriados na bacia do rio Grande.

\begin{tabular}{|c|c|c|c|c|c|c|}
\hline Knickpoint & $\begin{array}{c}\text { Sigla no } \\
\text { Mapa }\end{array}$ & $\begin{array}{l}\text { Altitude } \\
\text { (m) }\end{array}$ & Litologia & Estrutura & Tipo & $\begin{array}{l}\text { Orientação } \\
\text { Drenagem }\end{array}$ \\
\hline Conquista & GD1 & 1.020 & Suíte Cordeiro & Fraturas e dique & Corredeira & NE \\
\hline Três Cachoeiras & GD2 & 1.020 & Suíte Cordeiro & $\begin{array}{l}\text { Veios de Quartzo e } \\
\text { fraturas }\end{array}$ & Queda & NW/N \\
\hline Alto curso Rio Negro & GD3 & 380 & Complexo Rio Negro & Fraturas e Foliação & Queda & $\mathrm{NE}$ \\
\hline Serra do Gavião & GD4 & 340 & Complexo Rio Negro & Fraturas & Queda & $\mathrm{NE} / \mathrm{N}$ \\
\hline Duas Barras & GD5 & 440 & Complexo Rio Negro & Foliação & Corredeira & NE \\
\hline Barra do Veado & GD6 & 240 & Unidade São Fidélis & Foliação & Corredeira & $E$ \\
\hline Riograndina & GD7 & 720 & Suíte Serra dos Órgãos & Fraturas & Queda & $\mathrm{NE}$ \\
\hline Bairro Santa Teresa & GD8 & 580 & Suíte Serra dos Órgãos & Fraturas e Foliação & Corredeira & $\mathrm{NW} / \mathrm{N}$ \\
\hline Bom Jardim & GD9 & 560 & Complexo Rio Negro & Foliação & Queda & $\mathrm{N} / \mathrm{NE}$ \\
\hline Jusante de Bom Jardim & GD10 & 540 & Complexo Rio Negro & Fraturas & Corredeira & $\mathrm{N}$ \\
\hline PCH Santo Antônio & GD11 & 500 & Unidade São Fidélis & Fraturas & Queda & E/SE \\
\hline PCH Santa Rosa & GD12 & 440 & Unidade São Fidélis & Fraturas e Foliação & $\begin{array}{c}\text { Corredeira e } \\
\text { Queda }\end{array}$ & SE \\
\hline Fazenda Barra Grande & GD13 & 480 & Unidade São Fidélis & $\begin{array}{c}\text { Foliação e veios de } \\
\text { quartzo }\end{array}$ & Corredeira & SE \\
\hline Garganta do Roncador & GD14 & 240 & Unidade São Fidélis & Fraturas e Foliação & $\begin{array}{c}\text { Corredeira e } \\
\text { Queda }\end{array}$ & SE/S \\
\hline Manuel de Morais & GD15 & 240 & Suíte Desengano & Fraturas & Queda & $\mathrm{E} / \mathrm{NE}$ \\
\hline Renascença & GD16 & 80 & Unidade São Fidélis & Foliação & Corredeira & NE \\
\hline Cabeceira Rio Negro & GD17 & 800 & Suíte Cordeiro & $\begin{array}{c}\text { Fraturas e Dique de } \\
\text { Diabásio }\end{array}$ & Queda & NE \\
\hline
\end{tabular}




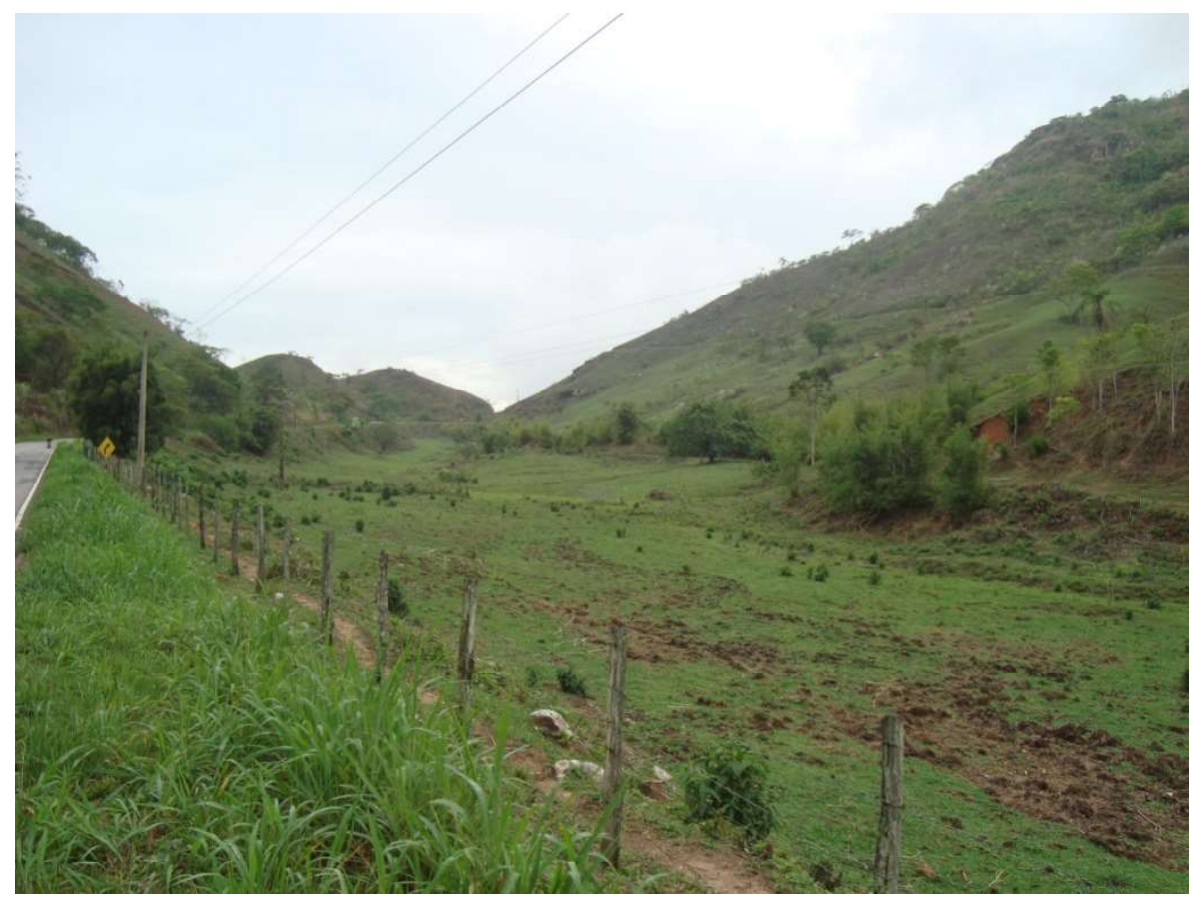

Figura 10 - Vale abandonado pela drenagem após a captura próxima à localidade de Euclidelândia. Foto com visada para norte.

Acredita-se que os rios pretéritos correspondiam à frente de dissecação da Serra das Águas Quentes nesta localidade e conseguiram capturar o rio Negro nesse setor pelo avanço de sua cabeceira. Acredita-se que o mesmo aconteceu com o rio Macuco e drenagens que estavam suspensas por este patamar topográfico ou antigos planaltos. Estas capturas podem ser consideradas como resultado do RCSBque promoveu rebaixamento do nível de base atlântico e reordenou os sistemas fluviais da região. Diante disso, as bacias de drenagem marginais expandiram sua área de contribuição pelo recuo de cabeceiras e capturas de drenagem do antigo planalto no sudeste - pré-cretáceo, como no caso do rio Negro.

\section{Considerações Finais}

Na bacia do rio Grande, percebe-sea influência da geologia na compartimentação topográfica. Ao cruzar os dados geológicos e hipsométricos, observou-se que as rochas mais resistentes ao intemperismo e erosão, como os granitos pós-tectônicos, representam as altitudes mais elevadas da bacia, enquanto que as rochas menos resistentes, como os gnaisses da Unidade São Fidélis, são mais rebaixados. Isto pode ser evidenciado pelo divisor sul da bacia do Rio Grande, representado pelo reverso da Serra do Mar que é um imponente divisor preservando o relevo montanhoso elevado. Outra evidência da resistência dos granitos está associada à presença de relevo no formato pães-de-açúcar, como no caso do Duas Pedras em Nova Friburgo, que permanecem preservados apesar de estruturas rúpteis condicionarem a formação de vales encaixados no seu entorno.

Vale destacar, o forte controle dos lineamentos na orientação da rede de drenagem, com destaque para os lineamentos N60E que influenciaram na grande quantidade de rios com fluxo para nordeste. Boa parte da calha principal do rio Grande está condicionada neste sentido, principalmente influenciada pela foliação das rochas, contudo, possui inflexões na orientação da drenagem ocasionadas por fraturas.

Os topos coincidentes e fundos de vale com altitudes similares identificados nos perfis topográficos contribuem para a identificação dos planaltos relictos, assim como, os níveis de base que controlam a dissecação da bacia. Já no perfil longitudinal do rio Grande podem ser observadas rupturas de declive que interrompem superfícies mais suaves pelas quais este rio drena. Esses dados reforçam a ideia do controle do nível de base na evolução da drenagem e dissecação do relevo. Este controle foi condicionado, principalmente, pela erosão diferencial das rochas, devido à maior ou menor resistência de cada litotipo.

Estas capturas contribuíram para a dissecação do 
antigo planalto e para reordenar o sistema fluvial da região. A elevada quantidade de anomalias de drenagem do tipo cotovelo, com inflexões para NE evidenciam a eficiência do rio Grande na captação das drenagens da região. Os dados demonstram que a calha aproveitou os planos de fraqueza do substrato rochoso para avançar suas cabeceiras, alternando entre a foliação das rochas e as fraturas da região.

Por fim, acredita-se que o Planalto Sudeste brasileiro, pré-abertura do RCSB, configurava-se por uma área de grande extensão e de maior elevação altimétrica em relação à atual, com sistema fluvial que drenava para o interior da placa. A evolução do rio Grande se deu por meio de capturas das paleodrenagens que se situavam sobre o antigo planalto sudeste, influenciadas diretamente pelas estruturas geológicas, com destaque para a foliação dos gnaisses da Unidade São Fidélis. Este avanço da rede de drenagem do rio Grande promoveu a formação de anomalias de drenagem e dissecação do relevo pelo ajuste ao novo nível de base. Contudo, a erosão diferencial proporcionada pela resistência litológica dos Granitos ainda preserva o relevo, bem como vales suspensos sustentados por knickpoints.

\section{Referências Bibliográficas}

AB'SABER, A. N. O problema das conexões antigas e da separação da drenagem do Paraíba e do Tietê. Geomorfologia 26. São Paulo, Instituto de Geografia da USP, p. 38-49. 1957.

ALMEIDA, F. F. M.; HASUI, Y.; BRITO-NEVES, B. B.; FUCK, R. A. BrazilianStructuralProvinces: na introduction. EarthSci. Rev., 17: 1-29. 1981

ALMEIDA, F. F. M. \& CARNEIRO, C. D. Origem e evolução da Serra do Mar. Revista Brasileira de Geociências, no 28(2), pp. 135-150. 1998.

ASMUS, H.E. \& FERRARI, A.L. 1978. Hipótese sobre a causa do tectonismo cenozóico na região sudeste do Brasil. Projeto REMAC, 4,p.75-88.

BIGARELlA, J.J. \& MEIS, M.R. M. Considerações a respeito dos terraços fluviais, rampas de colúvios e várzeas. BoletimParanaense de Geografia, Curitiba. 16/17: 153-197, 1965.

BISHOP, P. Drainage rearrangement by river capture, beheading and diversion.Progress in Physical Geography, v.19, n.4, p.449-473.1995.
CHEREM, L. F. S.; VARAJÃO, C. A. C.; BRAUCHER, R.; BOURLÉS, D.; SALGADO, A. A.; VARAJÃO, A. C. Longterm evolution of denudational escarpments in southeastern Brazil. Geomorphology. v. 173-4. p. 118-27. 2012.

CHRISTOFOLETTI, A. Considerações sobre o nível de base, rupturas de declive, capturas fluviais e morfogênese do perfil longitudinal. Geografia, 2 (4), p. 81-102. 1977.

COELHO NETTO, A L. Catastrophic Landscape Evolution in a Humid Region (SE Brazil): inheritances from tectonic, climatic and land use induced changes. Supplementidi Geografia Fisica e Dinamica Quaternária, Supp. III, Tomo 3: 21-48. 1999

COELHO NETTO, A L. Evolução de Cabeceiras de Drenagem no Médio Vale do Rio Paraíba do Sul (SP/RJ): a Formação e o Crescimento da Rede de Canais sob Controle Estrutural. Revista Brasileira de Geomorfologia, Ano 4, No 2 69-100. 2003.

DANTAS, M. E. Controles naturais e antropogênicos na sedimentação fluvial, espacialmente não uniforme, na bacia do rio Bananal (SP/RJ): Médio Vale do rio Paraíba do Sul; (Mestrado) PPGG/UFRJ. Dissertação e Mestrado, Departamento de Geografia, UFRJ. 1995.

DANTAS, M. E. Mapa geomorfológico do Estado do Rio de Janeiro. In: CPRM - Estudo Ambiental do Estado do Rio de Janeiro. Brasília (DF): Ministério de Minas e Energia. 2001. CD-ROM.

FERRARI, A. L. Evolução tectônica do Gráben da Guanabara. Tese (Doutorado), Instituto de Geociências, Universidade de São Paulo.p.412. 2001.

HARTWIG, M. E.; RICCOMINI, C. Análise morfotectônica da região da Serra dos Órgãos, Sudeste do Brasil. Revista Brasileira de Geomorfologia, v. 11, nº 1, p. $11-20,2010$.

HEILBRON,M., PEDROSA-SOARES,A.C., CAMPOS NETO,M.C., SILVA,L.C., TROUW, R.A.J.; JANASI,V.A., Província Mantiqueira. In: MANTESSO-NETO,V. BARTORELLI,A., CARNEIRO,C.D.R. e BRITO-NEVES,B.B., Orgs. Geologia do Continente Sul-Americano: evolução da obra de Fernando Flávio Marques de Almeida. São Paulo, Ed. Beca, p.203-236. 2004

HEILBRON,M., VALERIANO,C.M., VALLADARES,C.S. e MACHADO,N., A orogênese Brasiliana no segmento central da Faixa Ribeira, Brasil. Revista Brasileira de Geociências, 25(4): 245-266. 1995.

HEILBRON, M.; EIRADO, L. G.; ALMEIDA, J. (Orgs.). Geologia e Recursos Minerais do Estado do Rio de Janeiro. 
Belo Horizonte. 2016.

LEOPOLD, L. B.; WOLMAN, M. G.; MILLER, J.P. Fluvial Processes.In Geomorphology. San Francisco. W. H. Freeman Co, 1964. p. 522.

LIMA, C. C. U. O.Neotectonismo na Costa do Sudeste e do Nordeste Brasileiro. Revista de Ciência \& Tecnologia, v. 15, p. 91-102, 2000.

MEIS, M.R.M. \& MONTEIRO, A.M.F. UpperQuaternary rampas: Doce rivervalley, SE BrazilianPlateau. Zeit. Geomorph., 23: 132- 151. 1979.

MIRANDA, E. E. de; (Coord.). Brasil em Relevo. Campinas: Embrapa Monitoramento por Satélite, 2005. Disponível em: $<$ http://www.relevobr.cnpm.embrapa.br>. Acesso em: 15 jun. 2013.

MOURA, J. R. S.\& MEIS, M. R. M. Litoestratigrafia preliminar para os depósitos de encosta do Quaternário Superior do Planalto SE do Brasil (MG-RJ). Rev. Bras. Geoc.,10(4):258-267. 1980.

MOURA, J.R.S. As transformações ambientais do Quaternário Tardio do médio vale do rio Paraíba do Sul (SP/ RJ).Rio de Janeiro, 265p. (Tese de Doutorado - PPGGeol.-IGEO/UFRJ). 1990.

OLIVEIRA, D. A captura do Alto Rio Guaratuba: uma proposta metodológica para o estudo da evolução do relevo na Serra do Mar, Boracéia-SP. 105f.+anexos. Tese (Doutorado) - Departamento de Geografia-FFLCH-USP, São Paulo. 2003.

PASA, VANIZA. Estudo da Conexão entre as drenagens do Médio Paraíba do Sul e do Alto Tietê: O caso do cotovelo de Guararema-SP, Brasil. Dissertação (Mestrado). Departamento de Geografia, Universidade de São Paulo, São Paulo. 110 p. 2013

RICCOMINI, C. O Rift continental do sudeste do Brasil. Tese (Doutorado) - Instituto de Geociências, Universidade de São Paulo, São Paulo.256 p. 1989.

RICCOMINI, C.; SANT'ANNA, L. G.; FERRARI, A. L. Evolução geológica do Rift Continental do Sudeste do Brasil. In: MANTESSO-NETO, V.; BARTORELLI, A.; CARNEIRO, C. D. R; BRITO NEVES, B. B. (Org.). Geologia do Continente Sul-Americano: evolução da obra de Fernando Flávio Marques de Almeida. São Paulo: Beca, p. 383-405. 2004.
RICCOMINI, C.; GROHMANN, C. H.; SANT'ANNA, L. G.; HIRUMA, S. T. A Captura das Cabeceiras do Rio Tietê pelo Rio Paraíba do Sul. In: MONDENSEI-GAUTTIERI, M. C.; BARTORELLI, A. CARNEIRO, C. R. LISBOA, M. B. A. L. A Obra de Aziz NacibAb'Sáber. São Paulo: Beca-BALL edições, 2010.

RUELLAN, F. Evolução geomorfológica da Baía de Guanabara e das regiões vizinhas. Revista Brasileira de Geografia, 6(4): 445 - 508. 1944.

SILVA, T.M. Evolução Geomorfológica e Sedimentação de Canais Erosivos Holocênicos no Médio Vale do Rio Paraíba do Sul. Programa de Pós-Graduação em Geografia, Universidade Federal do Rio de Janeiro, Dissertação de Mestrado, 165p. 1991.

SILVA, T.M.; MONTEIRO, H.S.; CRUZ, M.A.; MOURA, J.R.S. Anomalias de drenagem e evolução da paisagem no médio vale do rio Paraíba do Sul (RJ/SP). Anuário do Instituto de Geociências (Rio de Janeiro), v. 29, p. 210-224. 2006.

SILVA, T. M.; SANTOS, B. P. Sistemas de Drenagem e Evolução da Paisagem. Revista Geogr. Acadêmica v.4, n.1, 5-19. 2010.

TUPinAMBÁ, M.; HeIlbron, M.; DUARTE, B. P.; NOGUEIRA, J. R.; VALLADARES, C.; ALMEIDA, J. C. H.; SILVA, L. G. E.; MEDEIROS, S. R.; ALMEIDA, C. G.; MIRANDA, A.; RAGATKY, C. D.; MENDES, J.; LUDKA, I. Geologia Da Faixa Ribeira Setentrional: Estado Da Arte E Conexões Com A Faixa Araçuaí. GEONOMOS 15(1): 67 - 79, 2007.

TUPINAMBÁ, M. (coord). Nota Explicativa da Folha Nova Friburgo 1:100.000. CPRM-UERJ. PRONAGEO. CD-ROM. 2012.

TUPINAMBÁ, M.; TEIXEIRA, W.; HEILBRON, M. Evolução Tectônica e Magmática da Faixa Ribeira entre o Neoproterozoico e o Paleozoico Inferior na Região Serrana do Estado do Rio de Janeiro, Brasil. Anuário do Instituto de Geociências - UFRJ. Vol. 35 - 2, p.140-151. 2012.

ZALÁN, P. V.; OLIVEIRA, J. A. B. Origem e evolução estrutural do Sistema de Riftes Cenozóicos do Sudeste do Brasil. Boletim de Geociências Petrobras, Rio de Janeiro, v. 13, n. 2, p. 269-300, maio/nov. 2005. 